\title{
Culture-based artefacts to inform ICT design: foundations and practice
}

\author{
Lara S. G. Piccolo ${ }^{1} \cdot$ Roberto Pereira ${ }^{2}$
}

Received: 1 March 2016/ Accepted: 3 July 2017 / Published online: 12 July 2017

(c) The Author(s) 2017. This article is an open access publication

\begin{abstract}
Cultural aspects frame our perception of the world and direct the many different ways people interact with things in it. For this reason, these aspects should be considered when designing technology with the purpose to positively impact people in a community. In this paper, we revisit the foundations of culture aiming to bring this concept in dialogue with design. To inform design with cultural aspects, we model reality in three levels of formality: informal, formal, and technical, and subscribe to a systemic vision that considers the technical solution as part of a more complex social system in which people live and interact. In this paper, we instantiate this theoretical and methodological view by presenting two case studies of technology design in which culture-based artefacts were employed to inform the design process. We claim that as important as including issues related to culture in the ICT design agenda-from the conception to the development, evaluation, and adoption of a technology - is the need to support the design process with adequate artefacts that help identifying cultural aspects within communities and translating them into sociotechnical requirements. We argue that a culturally informed perspective on design can go
\end{abstract}

AIS Volume: Special issue: Cultural Diversity and Community Technology Design (CulTech)-volume to be allocated later.

Lara S. G. Piccolo

lara.piccolo@open.ac.uk

Roberto Pereira

rpereira@inf.ufpr.br

1 Knowledge Media Institute, The Open University, Walton Hall, Milton Keynes MK7 6AA, UK

2 Department of Informatics, Federal University of Paraná (UFPR), Curitiba, Brazil beyond an informative analysis, and can be integrated with the theoretical and methodological framework used to support design, throughout the entire design process.

Keywords Human-computer interaction · Culture and values in design - Organisational semiotics . Socially aware design

\section{Introduction}

Historically, technology development studies and research for understanding human culture have been split by an epistemological barrier. But the recent and broad impact of technology on people's lives has blurred this boundary, requiring more dialogue and cooperation between-and beyond-both domains. An interchange of perspectives and methods has been necessary to design new meaningful Information and Communication Technologies (ICTs) and to understand the influence of ICTs on people's lives. This sociotechnical approach to design also paves the way for creating new ICTs for the common good, such as for enabling and empowering groups of people to deal with challenges and threats (Pipek et al. 2016), strengthening communities, reinforcing social solidarity, or addressing disadvantage issues (Gurstein 2007).

New fields of study like Community Informatics (Gurstein 2007) have emerged in the past decades integrating different research domains and pursuing this positive social impact. Moreover, some "hard" sciences have expanded their inner boundaries to better understand how people perceive a technology, how they appropriate it, and how they are affected by it. In Computer Science, these studies are in the context of the (inter)discipline human-computer interaction (HCI). Since it became a field in the 80s, HCI 
has evolved from ergonomics and cognitive modelling to embracing more social and subjective aspects of humans' lives, such as values and culture (Rogers 2012). In this context, culture can be understood as the set of knowledge, beliefs, art, morals, and any other capabilities and habits shared within a social group (Tylor 2010), which influence the way individuals or communities perceive the world and interact with it.

Culture, Communities, and ICT Design have been investigated and discussed from a multitude of perspectives and conceptual backgrounds-e.g., Bødker et al. (2003), Kamppuri et al. (2006), Leidner and Kayworth (2006) and Halabi et al. (2015), to cite a few. It is a common understanding, though, that establishing a culture of informing ICT design with cultural aspects still demands efforts that start from revisiting theoretical and methodological grounds and practices. It is both a matter of action and perspectivetaking, which requires a shift in our position as researchers, scientists, and practitioners, seeing the people before the problem, the social impact before the technology, and the actual needs of users and stakeholders ahead of automating tasks. In fact, as important as including issues related to culture in the ICT design agenda-from the conception to the development, evaluation, and adoption-is the need to support the design process with adequate artefacts that help identifying cultural aspects within communities and translating them into sociotechnical requirements.

In this paper, we ground our discussions on socially aware computing, an approach to ICT design conceived by Baranauskas (2009, 2014). This approach models reality in three levels that influence each other: the technical, or the "tangible world" where the ICTs are situated; the formal, where existing rules shape our behaviour; and the informal, composed by values, beliefs, motivations, and other aspects that influence how we perceive the world. Based on this conceptual approach, we explore four artefacts/strategies we applied in practice: (i) the organisational onion; (ii) the primary message systems (PMS); (iii) social norms; and (iv) the value pie, which we have developed ourselves. The artefacts are explained and illustrated considering two complementary case studies with different communities and contexts in Brazil: the first one for raising collective awareness of energy consumption and conservation; the second to mediate the socialisation of educational practices related to students with special needs.

In the next three sections of this paper we shed light on (i) our perspective on culture; (ii) the rationale for informing ICT design with cultural aspects; and (iii) how the fields of ICT design and community informatics have dealt with cultural aspects, bringing perspectives from the literature. We then present the four culturally informed design artefacts and explain how they have been used in the contextual studies, allowing us to discuss how they can support design and benefit the communities involved.

\section{Our perspective on culture}

According to Tylor (2010), the term "Culture" emerged in 1871 as a synthesis of the terms "Kultur" and "Civilization", used to refer to all the spiritual aspects of a community and their material achievements, respectively. Culture, in its wide and ethnographic sense, represents the complex wholeness that includes knowledge, belief, art, morals, law, custom, and any other capability and habit acquired by a human being as a member of a society.

Hofstede (2005) offers a perspective on culture that relies on shared beliefs, values and practices of a group of people, as the collective programming of mind that distinguishes the members of one culture from the members of another. Stamper et al. (2000) develop a similar argument that the shared norms between people are what define a culture. Barth (1969) introduces a different cultural-anthropological notion suggesting that is not a cultural core that defines a group, but the boundaries: they delineate the identity of the community, making clear the distinct aspects. For Bødker et al. (2003), Barth's approach helps focus on contexts and situations in which boundaries are generated.

Hall (1977) argues that the natural act of thinking is strongly modified by culture and believes that more important than looking at theories with a specific cultural focus, is looking at the way different aspects that influence our perception, behaviour and understandings are put together. Questioning about specific situations may already provide interesting insights, but understanding the cultural context in which people live, the way they interact, and their behavioural patterns can provide richer results than looking at predefined hypotheses relating people and their perception of things in life.

In Hall's perspective (1959), culture is understood as different ways of organising life, thinking, and understanding basic assumptions about the family, the state, the economic system, and the human being, acting as a link between humans and the means of interacting with each other. Hall's approach is based on 10 Primary Messages Systems of communication, or areas, that he named the basic building blocks of culture: Interaction, Association, Learning, Play, Protection, Exploitation, Temporality, Territoriality, Classification, and Subsistence. He argues that any culture can be characterised, analysed, and compared through a combination between these areas. Culture is then analysed as a form of communication giving emphasis to the non-verbal aspects (behaviours, values, intentions, needs, expectations, etc.). Learned behaviour 
patterns, attitudes, values, and material goods are under a cultural context, being developed according to these areas.

Another important contribution of Hall's work (1959) is the notion of the informal, formal, and technical levels in which humans operate and understand the world. According to him, each level is present in any situation, but one will always dominate in a given instant of time, and is analysed separately. Sometimes, the shifts (and boundaries) between these levels are subtle and rapid, but understanding them and their shifts would be the basic requirement to understand the process of cultural change. For instance, Hall (1959) sees learning as a basic activity in life, arguing it is one of the most representative characteristics of a culture: people may learn from observing other people and imitating them (informal); from other's explicit feedback, suggestions and instructions (formal); or from books, guidelines and other materials that explain and justify things in a coherently outlined form (technical). In all these levels of learning there may be values and preferences involved (informal), as well as rules and (not) acceptable behavioural patterns (formal), as well as objects and materials (technical) and so on. It is also possible to see the three levels in action when considering technology adoption in educational practices. There are several informal issues at play, mainly emotional and affective constructs, such as students' motivations and teachers' openness to change. There are also formal issues that must be understood and followed, such as the laws, the teaching program and the students' minimum age. And there are technical issues, which range from choosing the right educational technology that respects the formal issues and is in conformity with the informal ones, to the physical structure and available resources, such as the learning space, internet access, network security, etc. All the issues mentioned are equally important and vary strongly from a cultural context to another, indicating that it is not possible to understand ICT and its impact detached from the cultural context in which it is designed, delivered and used.

Hall $(1959,1977)$ is then our main theoretical reference both to understand how culture and design are related and to inform our process of designing technology. In our perspective, Hall's foundation enriches the design context and enables designers to look at the world through the lenses of different stakeholders and to deal with different levels of formalism.

\section{The role of culture in ICT design}

“... Technology is not given. It's not like the sun or the moon or the stars. It was made by people like us. If it's not doing for us what we want, we have a right and a responsibility to change it." (Mike Cooley, Right Livelihood Award Speech, ${ }^{1}$ 1981).

Drawing attention to the impact of technology on communities is not a recent issue, restricted to the digital era. In the mid-50s, Sharp (1952) analysed the introduction of the steel axe by a group of missionaries into a tribe. It was expected the steel axe would improve the tribe' productivity and quality of life, but an inevitable collapse of its traditional culture and values was triggered instead. This impact may have been caused by the technology itself, the way it was introduced, the way it was used, the interests behind it and so on.

Analysing the industrial design field in the 70s, Papanek (1971) brought attention to the need for socially and environmentally responsible design of products, tools and infrastructure, and for recognising designers' social and moral responsibility in this process. Criticising a culture centred on economic and technical issues, the author highlighted the impacts caused by the creation of products that promote harmful behaviours, or even mutilate and kill people, neglecting the social context of design, the target audience and the society in general.

Earlier examples of essential digital services not truly accessible by design or even harmful to the society keep emerging worldwide. This can be briefly illustrated by an e-gov platform in Brazil named eSocial, launched as mandatory for paying domestic work-related taxes. Critical design issues prevented the system from addressing particularities of users, and only one-third of users were able to comply with their obligations due to these constraints. The others were unfairly fined for the payment delay (Globo 2015). The examples illustrate real situations, and the last one demonstrates that disregarding social impact is still a contemporary issue, but on a growing scale as it comes to ICT.

Negative impacts brought about by technology introduction to a community or a society cannot be prevented or solved by focusing on technical issues only. Dealing with the "non-neutrality of technology design" (Baranauskas 2014) requires considering the sociocultural world in which solutions are used and people live in. However, simply situating a design solution into a context that merely attempts to reflect the real world or an artificial scenario that the designer is able to represent and explain is not enough. Only when involved as another interested party in co-creating a cultural context, together with community members, the social and political structures and the constraints of the natural environment, the designer will be able to explore the potential of ICT to tackle efficiently social issues, making information more accessible,

\footnotetext{
${ }^{1}$ http://www.rightlivelihoodaward.org/speech/acceptance-speechmike-cooley/ last access: December 1st, 2016.
} 
promoting new worldviews and social innovation (Murray et al. 2010). To this end, methods and tools to build this knowledge in different sociocultural contexts and to transform them into features or elements of design are necessary. We will further unpack these issues in the next sections.

\section{How cultural aspects have been addressed in HCI}

Culture has been addressed in HCI with different purposes, not necessarily dealing with the intentionality (and impact) of ICT on communities and societies. It has been employed in usability evaluations (Del Gado and Nielsen 1996; Yeo 2000; Winschiers and Fendler 2007), inspired design methods from a cultural perspective (Gasparini et al. 2011; Salgado et al. 2011) and discussed in terms of internationalisation/globalisation of user interfaces (Marcus 2001). Studies to support design activities were found by Salgado et al. (2013), and Pereira and Baranauskas (2015), the latest grounded in Hall's (1959) primary messages system.

Contextual design (Beyer and Holtzblatt 1997) is a usercentred design process that offers a set of methods to support the design of products based on the collection, interpretation and use of data about users in the field. The process provides a cultural model supporting designers to represent the most important culture and policy aspects that influence how work is conducted in an organisation, what constraints are placed on people and how they deal with those constraints to conduct their work (Holtzblatt and Beyer 2013). The model offers guidance to analyse the collected data, but no support is offered for further decisions and actions, from data collection to requirements identification.

Reviewing 28 culture-related studies from the HCI literature, Kamppuri et al. (2006)categorised three main approaches: (i) considering culture as a characteristic of a user based on cognitive psychology, favouring formal experiments and surveys as methods (57\% of the analysed studies); (ii) studying the immediate cultural context of a user (18\% of the studies); (iii) studying culture as a larger system, addressing the relationship between technology and culture, including topics such as cultural factors in the adaptation of technology (another 18\%), which is dominated by Hofstede's (2005) approach. However, as Salgado et al. (2013) argue, Hofstede (2005) assumes the existence of generalised cultural traits. If on the one hand it facilitates predicting the behaviour of large cultural groups, a nation for example, on the other hand it does not favour identifying the cultural aspects of a group in a particular context, such as a community.
From a community study perspective, to create an impact with ICT, Bødker et al. (2003) and Bødker (2015) suggest studying and addressing communities systematically, considering conflicts, boundaries, controversies and not least understanding our own role as designers/researchers/activists in this space. Instead of identifying boundaries, for Gurstein (2007) promoting social change by means of ICT resonates with distribution and execution of power. Understanding the power system then, is a way to understand communities' dynamics. Halabi et al. (2015), in turn, analysed three community-based projects in terms of aligning design intentions and brought to light some findings in terms of methodological approaches. The authors highlighted the importance of the knowledge produced in community interactions to determine the design goals. Exploratory methods, such as ethnography, appeared to be promising as triggers for engaging with, and contributing back to communities with knowledge that is already theirs in tacit form. However, this method usually results in identifying design implications, not design intentions.

From an HCI perspective, even considering some influential references, recent literature claims that research in culture has been guided by practical and specific problems and contexts, therefore, building a fragmented view (Pereira and Baranauskas 2015; Salgado et al. 2013, 2015). As Bødker (2006) highlights, most work has been presented in theoretical isolation and as a solitary technical solution. In this sense, while the literature argues it provides guidance, methods and examples on how we can actually understand and consider culture in technology design, Isomursu et al. (2011) highlight that existing models and approaches in literature tend to restrict the analysis, sometimes preventing the identification of important aspects that may emerge from the cultural context being analysed. Therefore, there is a need for artefacts and methods to support designers who have little or no background in social sciences, balancing between offering designers guidance and the liberty to inquire and understand the design context.

In the next section, we introduce socially aware computing (Baranauskas 2009, 2014), the sociotechnical approach we adopt, which is grounded in community participation in a situated design context and resonates with Hall's perspective on culture.

\section{A Socially aware approach to ICT design}

Socially Aware Computing (Baranauskas 2009, 2014), which we refer to as socially aware design, is an approach to ICT design informed by sociocultural aspects, responsive to real societal needs. The approach asks for an understanding of the socioeconomic and cultural reality, 
which refers to identifying the forces that are in play influencing the way people perceive the world (and technology), the way they interact with things and with others, their expectations, values, etc. It may also reveal important and desirable (or undesirable) aspects for a diversity of stakeholders, influencing the design rationale with issues that are not easily evidenced by traditional design processes.

This approach has organisational semiotics as theoretical frame of reference: a discipline that studies information and its functions in organised domains, such as a company, or a community. Through the lenses of semiotics, one's perception of the world is subjective, relying on the triad composed by the person, the ecological system and the signs in the world (Peirce 1867-1913). Organisational Semiotics provides methods and techniques for understanding and modelling information systems, considering social and human activities - and the diversity of perspectives-as part of this system (Liu 2000; Stamper et al. 2000). With the socially aware approach, Baranauskas (2014) applies organisational semiotics concepts and methods to inform ICT design, relying also on Participatory Design (Schuler and Namioka 1993) as a methodological influence.

For Baranauskas $(2009,2014)$, a technically centred perspective prevents those in a design context from making sense of the problem in a wider sense, restricting also the range of solutions that can be proposed. The metaphor of a "Semiotic Onion" (Stamper 2001) illustrates then the idea that technical aspects in design are within a formal level, where rules regulate the way people act. The formal level is, in turn, immersed in an informal level made up of cultural aspects, where people's beliefs, values and motivations are situated. The technical, formal, and informal levels influence each other.

When referring to culture as a set of norms shared among people, Stamper et al. (2000) classify norms according to their formality (i.e., informal, formal, technical), arguing that a community is formed by different kinds of norms that govern how its members behave. This understanding resonates with Hall's (1959) notion of the three levels in which humans operate and understand the world, termed as well technical, formal and informal, which provides a lens to understand ICT as part of a cultural context, permeated by values, emotions, expectations, needs, norms, laws, procedures, behavioural patterns and so on. In line with that, Baranauskas $(2009,2014)$ understands the design of ICT as a movement that starts in society (see the dashed ellipse in Fig. 1), crossing the informal information system layer where activities are conducted to clarify the design problem (e.g., identify the stakeholders, their cultural differences, needs, interests, expectations, etc.); then the design progresses from the Informal to the Formal Information System layer, where activities support requirements elicitation, the decisionmaking informed by the knowledge constructed during problem clarification and the solution modelling. The design process continues towards the construction of a technical layer through activities that support interactive prototyping, the codification and experimentation of design alternatives and their evaluation.

Such an approach has the following key characteristics:

- It demands the articulation of meanings of a social group in their informal and formal levels for the coconstruction of the system at the technical level.

- It recognises the other, and their differences, as essential to a systemic view of the design of interactive systems.

- It recognises the communication between parties as a culturally defined social phenomenon and proposes artefacts to mediate this communication to ensure their creative and collaborative involvement in design.

- It entrusts in the stakeholders the power to design and allows their creative and responsible involvement in design solutions.

- It is situated in a socioeconomic and cultural reality, without losing its location in the broader world.

In our understanding, Baranauskas' design process does not finish in the technical level, but continues crossing back to the formal and informal layers, showing that the design product has the potential to trigger changes not only on its own features, but also in formal social norms and procedures, in a community or organisation's practices, and in the people's activities and behaviours. Therefore, the environment, the shared understanding about the problem and its solution, as well as their importance to different stakeholders, change iteratively and incrementally.

From our practical experiences, we argue that the contribution of a culturally informed perspective on design can go beyond an informative analysis and should be somehow integrated with the theoretical and methodological framework used to support design, throughout any design process. Organisational Semiotics provides methods and artefacts that address aspects like stakeholders' concerns, patterns of behaviour, values, etc., such as the stakeholder identification diagram, valuation frame and norms, among others (Liu 2000).

In the next subsections, we explore a set of culturebased artefacts/strategies addressing cultural aspects within the socially aware design context.

\subsection{The organisational onion}

As previously described, every technical artefact designed for/with a community presupposes a formal system that determines forms and rules, which relies on the informal 
Fig. 1 Baranauskas' socially aware design model (Baranauskas 2009)

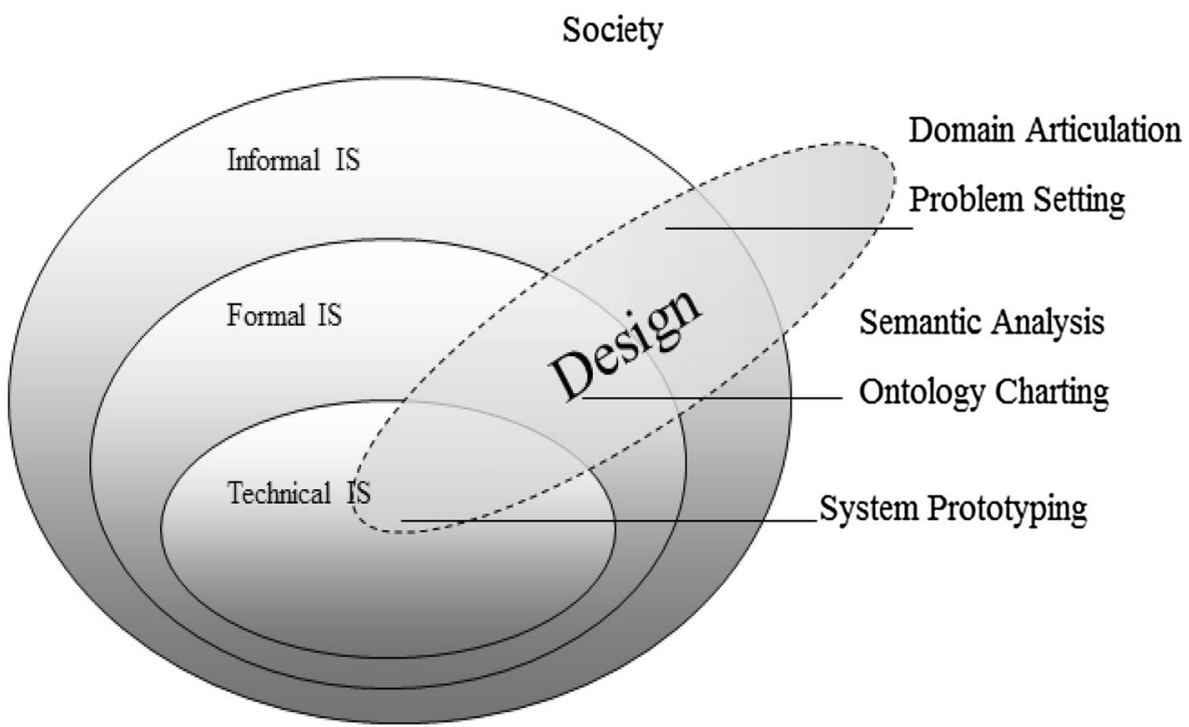

system with meaning, intentions, commitments and responsibilities of agents. The representation of the layers, as illustrated in Fig. 1, facilitates creating a panorama of the main forces in play influencing the ICT design, as well as an understanding of how the influence propagates between layers. In the organisational onion (Fig. 2), the ICT being conceived is placed on the core of the technical level, surrounded by other associated technical artefacts. The formal or informal forces such as some stakeholders' influence, shared values, norms and beliefs are in their respective layer, or sometimes across two layers (for example, some entities play formal and informal roles at the same time). An example of a generic organisation onion is illustrated in Fig. 2. Rules and Regulation are situated in the formal layer. The community organisation, or its structure, may be situated somewhere in between the formal and informal levels. In the informal layer are situated habits, values, beliefs and motivations. An instance of

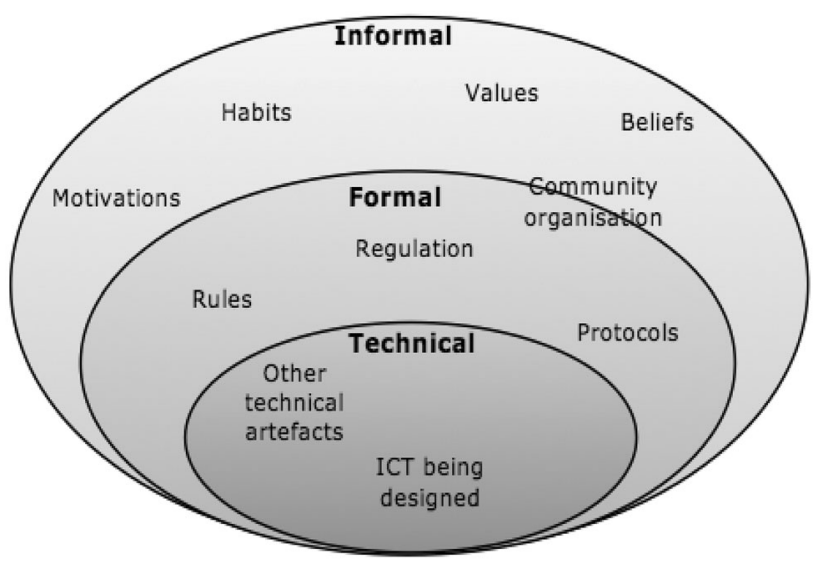

Fig. 2 Example of a generic organisational onion the organisational onion will be described in the case studies section.

\subsection{Hall's primary message systems (PMS)}

As previously mentioned, Hall's approach considers ten main areas that culturally distinguish a social group (Hall 1959; Kolkman 1993). The PMS define this taxonomy with ten categories of implicit behaviours:

- Interaction describes the specific relation between people and their environment.

- Bisexuality refers to the behavioural differentiation according to gender, age, race, etc. More recently, Kolkman (1993) renamed bisexuality to Classification reflecting a wider meaning.

- Association: refers to how people interact with others and the social organisations.

- Learning and acquisition: means how the knowledge is transmitted from a biological origin to formal and informal learning processes.

- Defence: concerns how people defend themselves from hostile forces from nature and within the human society; including religion, medicine and law enforcement.

- Play: aspects of joy, competition, affection.

- Exploitation: refers to adaptations, including the material ones, to exploit the environment.

- Temporality: involves cycles and rhythms, how people deal with time.

- Territoriality: regards taking possession, use and defence of a territory.

- Subsistence: includes features, habits and processes from individual food habits to the economy of a country. 
As Hall (1959), p. 57) states, "each PMS is obviously so rich and complex that it can be made the subject of a lifetime's work". Thereafter, in the context of ICT design an analysis of these ten elements should not have the ambition of being complete, mapping all the complexity of a community. Rather, it intends to highlight aspects that could not be easily observed in traditional design processes, but strong enough to influence technology perception and use. Participatory activities with a community promoting self-reflection and situated discussion around these elements can help identifying and describing them, as found in Pereira et al. (2011). Data analysis from ethnographic studies, surveys, etc. can also be framed according to the PMS, as the example presented in the case study of this paper. In a complementary way, the Valuation Framing artefact from Organisational Semiotics (Liu 2000) suggests associating the ten areas of this cultural system with different stakeholders and their interests regarding the problem being handled.

\subsection{Mapping social norms}

Within the organisational semiotics framework (Liu 2000), a community, organisation or social group can be seen as a system of social norms (Stamper et al. 2000). The norms determine patterns of behaviour, and whether they are legal or acceptable within the social context, defining then a culture. Norms are developed as collective affordances through practical experiences of people, influencing how they perceive the world, make judgments and possibly guiding their behaviour and thoughts according to a subjective evaluation of a situation. Norms can be manipulated, applied and disregarded accordingly (Stamper 1993). Within Organisational Semiotics context, norms are structured as rules (Liu 2000):

for a certain community and a certain purpose,

if $\underline{x}$ then $\underline{A}$ is (obliged/permitted/forbidden) to do $\underline{y}$.

where $x$ is some perception of the situation, $A$ is a responsible agent (a person or group of people) and $y$ is the action. The agent $A$ can only act in accordance with the norms of the community for the given purpose if he/she/it has the information necessary for perceiving the situation and the power to communicate it. Once identified, the norms can be translated into system requirements. Norms are, therefore, a way to represent cultural issues, carrying them to the materialisation of an ICT, i.e., allowing to "translate" cultural issues into a computing feature.

\subsection{The value pie}

The value pie is a culturally informed conceptual scheme one of the authors created (Pereira and
Baranauskas 2014) on the grounds of Organisational Semiotics (Liu 2000) and Hall's PMS (Hall 1959). It supports the problem and context understanding from three different perspectives: Cultural nature, Formality and Interplay (see Fig. 3). Cultural nature means that values are developed according to an area of culture, and with possible intersections between different areas. Formality means that values are manifested on one of the three levels, but have aspects to be considered in all the three simultaneously. Interplay means that values are intertwined to each other, affecting and influencing each other in different ways.

The value pie is a conceptual artefact that can support the reasoning and discussion of existing concepts from a cultural perspective, regardless of the design process, techniques and tools adopted. The simple act of mapping a concept onto the different dimensions of the value pie provides a value-oriented and culturally informed view of the concept and related issues. For instance:

1. Look for critical/important concepts involved in the design context, e.g., accessibility, privacy, autonomy, property, etc.

2. Identify the slice (area of culture) most related to it (if more than a slice is suitable, see which one is the dominating and consider the other as a related area). Accessibility, for instance, may be related to the "Exploitation" area, i.e., it is as a value related to the exploration of the world.

3. Investigate the informal, formal and technical aspects related to the selected concept (e.g., accessibility):

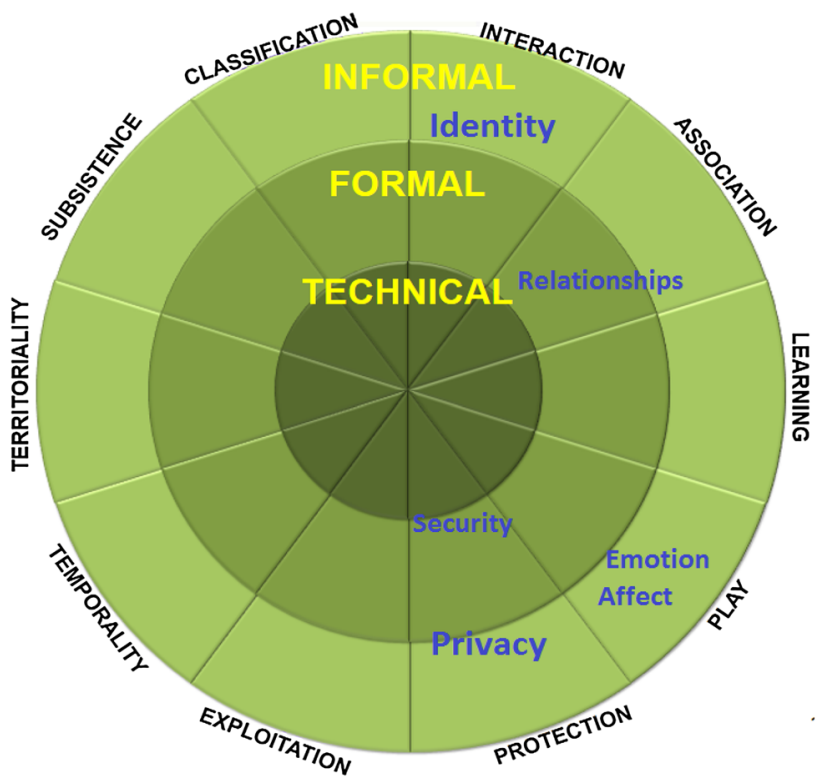

Fig. 3 The value pie (Pereira and Baranauskas 2014) 
a. Informal: different stakeholders have different values and react to accessibility in different ways (e.g., a disabled person will value ramps and lifts very differently from a non-disabled one);

b. Formal: there are rules, laws and norms related to accessibility that must be understood and followed (e.g., standards and certifications, requirements for accessibility). Even if no formal regulation is found, there will be well-accepted social norms that explain how a society deals with a given issue.

c. Technical: there are physical structures, tools and technical devices for enhancing accessibility (e.g., assistive technologies); there are public and private services related to accessibility, technical procedures, frameworks, etc.

4. Analyse the relationships of the concept with other areas: accessibility has a clear relationship with the interaction area (i.e., it allows interaction to happen) and is commonly approached according to predefined criteria/types (classification)_e.g., kinds of impairments, ageing, and education. Physical accessibility is related to territoriality and may depend on the time (e.g., having something available); the (lack of) accessibility may affect values related to subsistence and can put an individual in a risk situation (defence/ protection), etc. Each area may offer a different perspective on the concept being considered, favouring a wider perception regarding its impact on the design context.

Several authors have argued that understanding the context is the most critical activity in the design process (Bannon 2011; Sellen et al. 2009; Winograd 1997). The value pie artefact can be used both as lens to look at the design context from a wide, yet structured, social perspective and to understand specific concepts in a comprehensive and informed manner. When used to look at the design context, the artefact value pie warns designers to the existence of informal, formal and technical aspects (elements, attributes, behaviours, rules, values) related to the way the stakeholders interact (to each other, the environment, technology), associate, learn, play, deal with time and space and so on.

When applied to discuss specific concepts (e.g., accessibility, identity, privacy), the value pie invites designers to think about the concept according to value pie's different dimensions. One could imagine a concept "floating" through the slices and layers of the Value Pie: although we tend to find a place where the concept is clearly manifested, we can see and discuss how it is related to the other layers and slices. In the dimension of formality, designers will look at the given concept according to its informal, formal and technical aspects: informal-the way different stakeholders understand and value it; formal - the (existing, new) social norms, laws and rules related to the value; technical-the technical solutions, objects, materials related to it, or which need to be developed/redesigned. In culture, designers will identify the area (or areas) of culture where the concept has originated, and in Interplay, they will reason about the possible influences it can cause/suffer from space, time, subsistence, learn and the other areas of culture, as well as other concepts.

For instance, consider the word "Privacy" in Fig. 3. It is formally defined by the Oxford Dictionary ${ }^{2}$ as " 1 . A state in which one is not observed or disturbed by other people; 1.1. The state of being free from public attention". In the Value Pie, privacy may be understood as a cultural value developed in the Protection area, reflecting the importance of protecting personal information, ideas, things (exploitation), space (territoriality), etc. People have their own informal understanding for what privacy is and what it means, but also social norms and formal regulations, as well as technical devices and materials to guarantee it. Privacy is directly related to people's identity, impacts on their security and on their welfare, and both influences and is influenced by their affective and emotional states. What is necessary and/or expected to protect and why, what are the means to protect it, the extension and limits of privacy and the importance given to it are examples of aspects that differ strongly according to the culture being analysed and cross all the dimensions of the Value Pie.

Considering Baranauskas' perspective on the design of information systems $(2009,2014)$, the structure of the Value Pie suggests at least two core ideas on norms and values: 1) Each important concept or issue being discussed in ICT design has formal issues to be understood and considered, which may be represented by norms. Therefore, norms may act as the bridge between the informal and the technical levels, specifying the way technical features should work; 2) If ICT is not understood in a cultural context, the norms it operationalises tend to not make sense to users, not afford the behaviours they are used to in their social world and may trigger undesired side-effects on them and on their environment.

\section{Case studies}

In this section, we briefly introduce two case studies of ICT design targeting community strengthening, collaboration and social change. Informed by the socially aware design approach, the case studies illustrate how concepts and the culture-based artefacts previously described were applied.

\footnotetext{
2 https://en.oxforddictionaries.com/definition/privacy (last access: 30 November 2016).
} 
Both design studies are situated in Brazil, in distinct domains and with different purposes.

The first case study aimed to promote collective awareness of energy consumption by means of a social technology. As fully described in Piccolo et al. (2017), we first mapped the problem and the reality in the three levels, technical, formal and informal, defining an Organisational Onion. To shape the analysis on how people in the scenario perceive energy consumption and environmental protection, we applied Halls' PMS and then identified some social norms. The main findings were modelled into general guidelines to design a social technology to raise energy awareness (Piccolo et al. 2012; 2013).

In the second case study, we drew on Hall's theory to understand the cultural practices and views of Brazilian special education teachers. Through participatory activities, a group of teachers co-created requirements to design a web platform to support their teaching practice, as reported in Pereira and Baranauskas (2015). In the following sections, we illustrate the applicability of the culture-based artefacts previously presented in the two case studies and discuss the benefits of the approach.

\subsection{Promoting energy awareness}

The first case study summarised refers to promoting a new "social affordance", or patterns of behaviour shared in a community (Stamper 2001; Liu 2000), related to using energy. The study aimed to contribute to the urgent need of coping with the limits of the planet in terms of natural resources. Instead of targeting directly reduction of energy consumption, the technology designed intended to raise awareness about the impact of the energy on the natural environment, both individually and collectively, and bring into discussion possibilities to save energy respecting lifestyle and contextual circumstances. The study took place in the city of Sete Lagoas in an area that reflects the national average in terms of domestic electricity consumption, as well as the sociocultural diversity of the
Brazilian scenario. For this reason, this area has been selected to host a pilot deployment of smart grid technology by the local energy provider.

Five main steps summarise the situated design process: (1) Understanding the problem; (2) eliciting culturally informed requirements and guidelines; (3) identifying current and intended patterns of behaviour; (4) experimental setting; (5) impact evaluation. Different strategies for data collection and sources of information about the sociocultural context were employed: a survey within the community, interviews with stakeholders, official national statistical data, focus groups, and an ethnographic study from the literature. The survey was employed to understand, among other things, the perceptions connecting energy use and the environment, how people relate to each other in the community, as well as their eventual motivations to save energy. Interviews with stakeholders, such as the energy provider and staff in a local school, revealed the influence of social forces like drug trafficking and the social acceptance of illegal electricity connections. Data from national statistics and focus groups suggested mainly the typical appliances usage, consumption habits, and possibilities to change behaviour. To inform the design with a sociocultural analysis, we have employed the three conceptual artefacts associated with the socially aware approach, as summarised in Table 1 below.

The impact of the technology on the social group and the design decisions were evaluated in a study involving directly 24 students of a public elementary school and their families. The study assessed the influence of design features on people's motivation and engagement with the cause.

\subsubsection{Understanding the problem}

Illustrating the influence of technical, formal and informal aspects together on this social issue, in Fig. 4 the main elements identified as part of the problem are represented in their respective levels of the Organisational Onion, or in

Table 1 Artefacts of the socially aware approach: application and outcomes

\begin{tabular}{|c|c|c|c|}
\hline Design artefact & $\begin{array}{l}\text { Step in the design } \\
\text { process }\end{array}$ & Source of information & Outcome of the application \\
\hline $\begin{array}{l}\text { Organisational } \\
\text { onion }\end{array}$ & $\begin{array}{l}\text { Understanding the } \\
\text { problem }\end{array}$ & $\begin{array}{l}\text { National statistics, survey within } \\
\text { the social group, interviews with } \\
\text { stakeholders }\end{array}$ & $\begin{array}{l}\text { Understanding the problem by identifying main forces, } \\
\text { stakeholders, and the influences among them in the } \\
\text { technical, formal and informal levels }\end{array}$ \\
\hline PMS & $\begin{array}{l}\text { Eliciting requirements } \\
\text { and guidelines }\end{array}$ & $\begin{array}{l}\text { Survey and ethnographic study } \\
\text { from the literature }\end{array}$ & $\begin{array}{l}\text { Understanding how people perceive energy consumption and } \\
\text { environmental protection, translating it into design } \\
\text { requirements }\end{array}$ \\
\hline $\begin{array}{l}\text { Mapping social } \\
\text { norms }\end{array}$ & $\begin{array}{l}\text { Identifying current and } \\
\text { intended patterns of } \\
\text { behaviour }\end{array}$ & $\begin{array}{l}\text { Survey, interviews with } \\
\text { stakeholders, focus group }\end{array}$ & $\begin{array}{l}\text { Current patterns of behaviour in the community and "desired" } \\
\text { behaviours that should be promoted }\end{array}$ \\
\hline
\end{tabular}




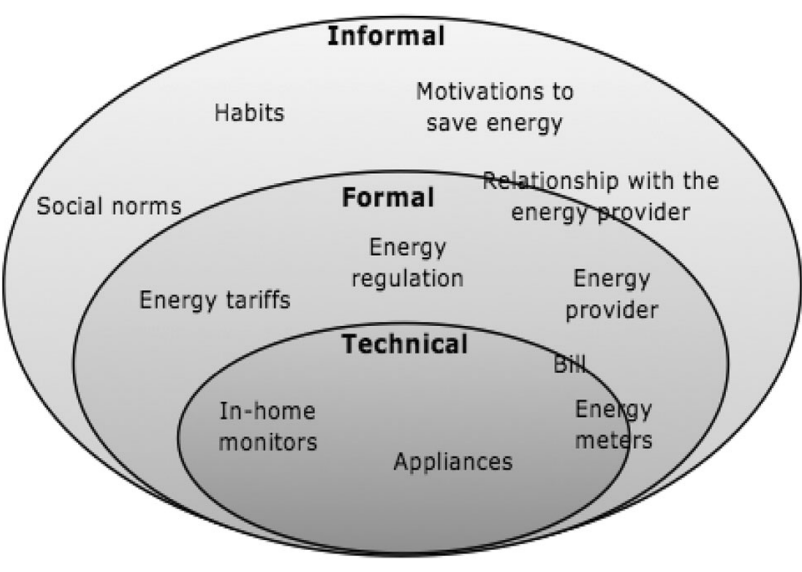

Fig. 4 Technical, formal and informal elements related to raise energy awareness

the border between them. Appliances and electronics, and how they can be operated efficiently, are in the technical level, together with in-home displays, eventually present in some households to provide feedback on consumption. Between the technical and formal levels are the official energy meters and the bill, the "physical" connection between the energy consumed and its supplier. Tariffs used and costs, current regulations, and the energy provider are in the formal level. The relationship with the energy provider, though, is in the border between formal and informal levels. As evidenced in our situated research (Piccolo et al. 2013), the perception of energy consumption is strongly affected by the relationship between the energy company and the customer, and the existing trust and respect (or lack thereof) (Piccolo and Baranauskas 2011). Concerns about the natural environment and the interest to save money are some of the possible motivations to save energy, in the informal level. Also in the informal level are situated the mainly unconscious habits of using energy and the social norms, the "I do it because everybody does it". These aspects influence each other and, all together, impact the way people perceive energy and energy consumption in daily life. Therefore, they need to be taken into account when designing a technology that aims to change this perception.

\subsubsection{Eliciting requirements informed by cultural aspects}

The next step goes towards transforming sociocultural aspects into technical requirements. Data obtained from a survey in the research scenario and an anthropological study from the literature (Almeida 2007) were analysed according to Hall's PMS (Piccolo et al. 2012). In Table 2, we illustrate this contribution with cultural forces found and the consequent design directions, highlighting some aspects that would not be easily observed in traditional design processes.

By evidencing the disconnection between individual attitudes to global consequences in Interaction, Association, Defence and Exploitation cultural aspects, one of the main findings of this analysis was to design for self-efficacy, making evident the impact of individual choices and actions. It also suggested social media and online games as tools to engage young people, as well as tangible alternatives for the elderly.

\subsubsection{Patterns of behaviour}

The sociocultural data collected via interviews with stakeholders, focus groups, and the survey within the community were also analysed and mapped as Norms (Piccolo et al. 2013), as this example illustrates:

$<$ MOST OF THE TIME, when in contact with people who do not pay for energy, THEN consumers MAY

believe that they should not pay for energy too.>

This norm reflects the fact that stealing electricity through illegal connections was somehow a culturally accepted behaviour. Other identified norms evidenced, for instance, that the traditional link between air pollution and energy generation/consumption adopted in eco-feedback design worldwide actually does not make sense for that community. People usually associate energy waste with wasting water due to the predominant hydroelectric power generation in their context. This analysis led to design elements such as associating energy waste with flooding new areas, and creating a space for people to freely discuss eventual illegal connections and collective consequences without fearing judgment.

This study considered the intentionality of the design in the process by modelling also the expected behaviour in the "intended reality" as Norms, as this example illustrates:

$<A L W A Y S$ when involved with a collective saving energy challenge THEN users MUST understand the importance of individual contributions to collective achievements.>

Considering these aspects among others (Piccolo et al. 2013, 2017), a technical artefact designed for raising collective awareness of energy, called SEEtree, was then proposed. The technical artefact is composed of an interactive system to set collective energy savings challenges compatible with the typical consumption in the area and a public and tangible feedback with led lights in the shape of a tree. Users' commitment, online and physical participations are translated into the number of tree branches that are lighted. Beyond the physical tree, the tree was also represented virtually as part of a forest, which could be 
Table 2 Examples of cultural aspects identified and impacts on design

\begin{tabular}{|c|c|}
\hline $\begin{array}{l}\text { PMS } \\
\text { elements }\end{array}$ & Aspects analysed and impacts on design \\
\hline Interaction & $\begin{array}{l}\text { Examining how people relate energy savings with natural environment protection, we concluded this connection is unclear or } \\
\text { almost non-existent. A new technology should focus on mediating that }\end{array}$ \\
\hline Classification & $\begin{array}{l}\text { Considered how different generations have used technology. Multiple solutions should consider social media for the younger and } \\
\text { other tangible, including non-digital artefacts, for people unfamiliar with ICTs }\end{array}$ \\
\hline Association & $\begin{array}{l}\text { How people in general make sense of individual and collective responsibility in the scenario suggested weak personal } \\
\text { commitment for global resources, pointing out the need to strengthen self-efficacy, the power of individual contributions to } \\
\text { solve a big issue }\end{array}$ \\
\hline Learning & $\begin{array}{l}\text { Lack of education was evidenced as a barrier to understanding abstract energy-related concepts such as } \mathrm{kWh} \text { and } \mathrm{CO}_{2} \text {. } \\
\text { Alternatives metaphors and comparisons to represent this data should be then considered }\end{array}$ \\
\hline Defence & $\begin{array}{l}\text { Explored the concept of "locus of control" that stems from psychology, studied by Almeida (2007) in an ethnographic analysis. } \\
\text { People that have an "external locus of control", believe that actions of powerful others, such as God or government, create } \\
\text { change. This belief is correlated with the educational level. People with an "internal locus of control", on the other hand, } \\
\text { believe in the consequences of their own actions and are more likely to take environmental actions. The "locus of control" } \\
\text { concept helps explain a lack of individual responsibility for externally triggered events that impact the environment, found in } \\
\text { the scenario }\end{array}$ \\
\hline Play & $\begin{array}{l}\text { Entertainment mediated through technology is an increasingly important cultural phenomenon. Official data about Internet usage } \\
\text { reported that around } 90 \% \text { of users spend time online for leisure and the most popular activity among connected children is } \\
\text { playing online games }\end{array}$ \\
\hline Exploitation & $\begin{array}{l}\text { Historic reasons and the abundance of natural resources in Brazil developed a "culture of waste". A restrained consumption of } \\
\text { food, energy, water, and raw material is not part of the common sense. Although the green consciousness started to emerge, } \\
\text { many people keep wasting natural resources and confuse saving resources with being greedy or miser }\end{array}$ \\
\hline Temporality & $\begin{array}{l}\text { Reducing energy consumption can have an immediate effect on saving money, but the benefits to the environment need to be } \\
\text { explained as a long-term investment. Money saving may not be enough to keep people's motivation }\end{array}$ \\
\hline Territoriality & $\begin{array}{l}\text { Organisations dedicated to socio-environmental issues usually develop local leaderships for spreading a sustainable exploration } \\
\text { of natural resources within a community. Using the same approach, a social technology can explore local social relations to } \\
\text { educate, locally instantiating consequences of individual attitudes and demonstrating the importance of their environment for } \\
\text { the global context }\end{array}$ \\
\hline Subsistence & $\begin{array}{l}\text { What are the overall resource requirements to sustain a particular lifestyle? This notion is not evident to anyone. Footprint } \\
\text { calculators }{ }^{\mathrm{a}} \text { are based on world averages and do not consider Brazilian particularities, such as hydroelectric plants, road } \\
\text { transportation, and the value of specific biomes such as the Amazon forest }\end{array}$ \\
\hline
\end{tabular}

${ }^{a}$ For example, http://footprint.wwf.org.uk

flooded to create a new dam if all the existing trees (groups of participants) did not contribute in the same way. Local natural elements, such as common species of trees or plants were also applied to represent users' territory. Students also received some paper artefacts to be taken home so that they could also engage their families in their group activities.

The SEETree was introduced in the technical level, triggering collaborative work to set up the saving challenges and promoting negotiation of possible energy saving behaviours in households. But it also impacted users' motivations and social norms, among other aspects. Figure 5 illustrates the new elements introduced, underlined.

In Piccolo et al. (2017), the interested reader can find more about the impact of the SEETree and all the complexity related to sociocultural variables in play when designing and evaluating a technology in real life, beyond the controlled environment of a lab.

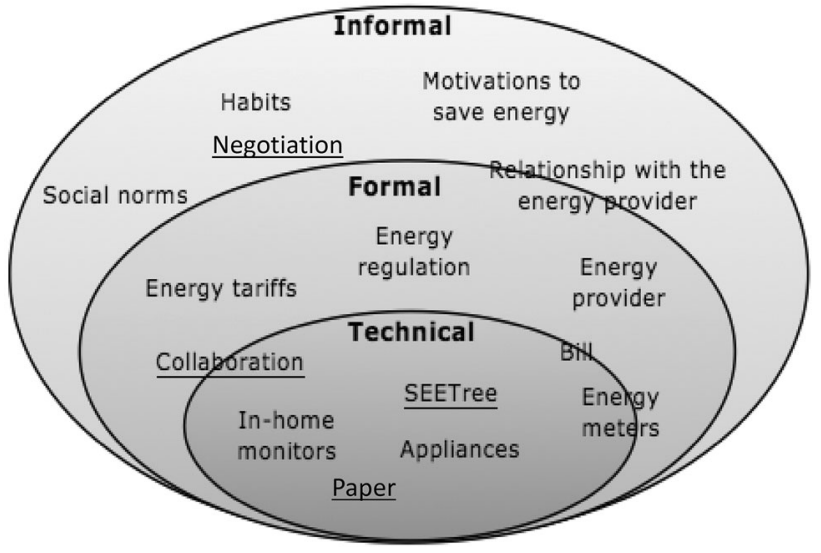

Fig. 5 New elements introduced (underlined) to raise energy awareness 


\subsection{Inclusive education scenario}

The second case study refers to the design of a social network, named TNR, Portuguese acronym for "All of Us Networked" ("Todos Nós em Rede"), which had the purpose to connect Inclusive Education teachers in Brazil, supporting the socialisation of their practices related to students with special needs and teachers' continuing professional development (Pereira and Baranauskas 2015).

By December 2016, TNR had more than 950 registered users, ${ }^{3}$ and more than 850 content items (articles, documents, questions, pictures) had been shared by teachers and received more than 4500 comments. The system was designed and is maintained in an iterative and incremental process informed by Baranauskas' Socially Aware approach, in which teachers are co-designers with active voice and role in the continuous design process and in the formation and maintenance of the network.

Inclusive education is a recent achievement in Brazil not yet free from political, pedagogical, and economic conflicts. As the world's fifth largest country in territory and population, the diversity of socioeconomic conditions and even ethnicity are remarkable; habits, behaviours, and needs also profoundly vary throughout the country. Teachers are often not yet used to computer technologies, and may have some impairment themselves (e.g., visual). They also have their own way of behaving, preferences, procedures, values, etc., that characterise them as a subculture that must be taken into account. In this scenario, designing a social network to connect teachers across the country to support collaboration and socialisation requires considering the different stakeholders, their culture (or subculture) as a group, the cultural differences between different groups of stakeholders, and the values they are adding to the design context.

To design the first version of TNR, a set of participatory activities was held from September 2010 to September 2012 involving 28 teachers, three researchers in Education, and four Computer Science and HCI researchers working together. The teachers were from different regions of the country and participated in both distance and face-to-face meetings that aligned design with social practices. Supported by the researchers, the teachers performed the following activities: (1) explored and evaluated existing systems towards supporting their teaching-related practices; (2) participated in brainstorming sessions and interviews; (3) created prototypes for the TNR; (4) provided feedback on the first version of TNR and joined online activities; (5) defined the system's terms of use and conditions; and (6) generated a letter of principles to guide the users' ethical behaviour in the system.

\footnotetext{
${ }^{3}$ Data from December 1st, 2016.
}

Because we tend to interpret the world through our own cultural lenses, the product of a design may result in a narrowed comprehension of the problem and the role of technology in people's lives; it may even mislead the design process, resulting in solutions that do not make sense to stakeholders, do not meet their demands and, possibly, trigger undesired side effects on them. In fact, most of the concepts and ideas we deal with when designing technology have different facets that are situational, varying not only according to the cultural context, but also across time and space. When we discuss such concepts, our discussion is a kind of snapshot in which some aspects are visible and some are not. To spot things beyond, we must take another snapshot, from a different angle. For this scenario, the Value Pie was used as a lens to look at the results of the participatory activities, supporting researchers to develop a wide, deep and meaningful understanding about the cultural context in which the system would operate.

\subsubsection{The value pie in practice}

Following the steps suggested in Sect. 5.4, the Value Pie application guided the analysis of existing systems (activity 1) and brainstorming sections with teachers (activity 2), as a conceptual framework for reflecting whether any important aspect was being neglected, and whether we considered the stakeholders' perspective beyond our own views. The Value Pie was also applied for the activity 6 by teachers for guiding their discussion and to identify the values they should make explicit in their letter of principles. Rather than following the application steps previously described, they used a set of values distributed over the Value Pie as a starting point for discussing their needs and aims.

Whether for triggering discussions or analysing results, the value pie supported us to look at the problem and information from different perspectives and to consider: (i) different levels of formalism (informal, formal, technical), (ii) cultural behavioural patterns-Hall's (1959) areas of culture, and (iii) relationships of interdependence with other issues being considered. Therefore, the Value Pie was a meta-artefact used to give a cultural meaning for the participatory activities.

For example, privacy appeared to be a critical concept for the system in the activities 1,2 and 6. When analysing the informal dimension of privacy related to learning, working (subsistence), protection (defence) and association, it was acknowledged that teachers did not explicitly express concerns of privacy: they actually found good to share their opinions and information, describe their practices and activities in the school and their work with students. However, with respect to security issues (e.g., 
someone sharing a photo of a student on Facebook) they became aware of possible impacts on their lives, on their students' or students' families' lives, leading then to a reflection around privacy. Usually, concerns like these emerge only during the system usage, when a problem arises. Therefore, the participants realised that the system should be designed not only to protect the stakeholders' privacy, but also to instruct users to be aware of it.

Understanding how privacy was valued and perceived by the teachers, and reflecting with them about how privacy could affect other stakeholders led to design decisions and TNR features-e.g., the new system must guide users regarding privacy and security issues, informing teachers about the possible consequences of their actions, and instructing them not to share any content that could compromise their privacy or the privacy of others. As an outcome, we specified norms such as " $<$ WHENEVER new data are created in the system, IF it contains personal information of others, THEN its author MUST have the authorization to use the information $>$ ", and < "WHENEVER a new content is shared to other users, IF it is publicly available, THEN the user MUST indicate that the content does not offer risks to his/her privacy and the privacy of others" $>$. Such norms were translated into design features and interface elements, such as an advice presented to users every time they are sharing a new content item into the system.

If we had ignored the stakeholders' cultural views on concepts that are well known to researchers, the design decisions could have led to a system that would cause privacy and security problems and whose impacts would be hardly possible to solve or mitigate. When we approach concepts from a cultural perspective, the cultural context explains the reason why these concepts are important, desirable and necessary for different stakeholders.

Yet another TNR example referred to the concept of reputation-see Fig. 6. Through the Value Pie's lens it was evidenced that, although teachers give importance to reputation and consider it is useful to identify the quality and relevance of the contributions made by other users, they think that every contribution is important and can bring benefits. When discussing a real problem, they believe that there is not a single best individual solution, but that one can be constructed by bringing together all the individual contributions (i.e., in a relationship between the association and classification areas). Using the teachers' words:

"I don't like the idea of choosing the 'best contribution', because it can generate a discomfort with the other participants. However, I think it is very interesting to have the possibility of identifying the quality of the contributions, although not defining the best

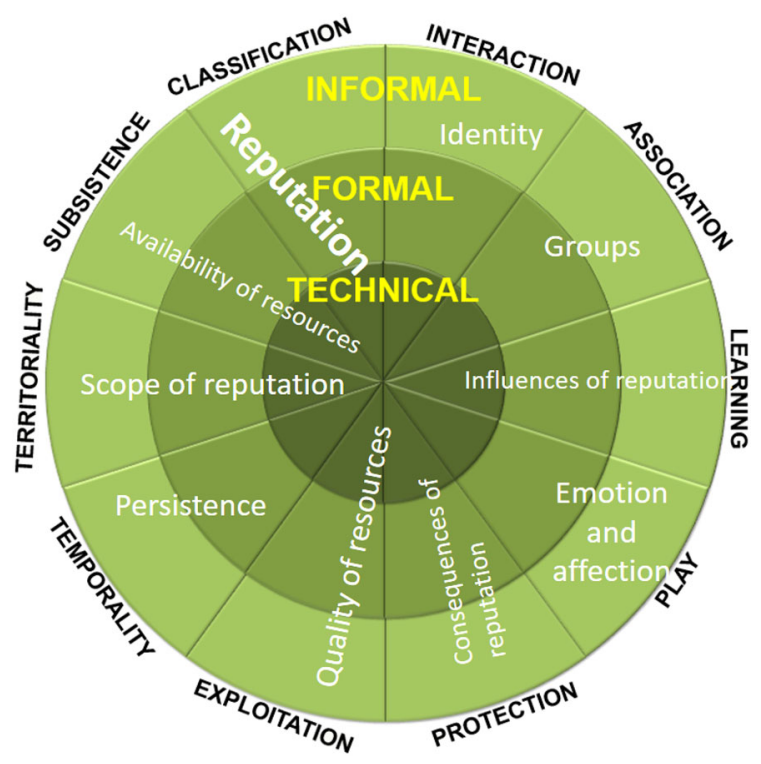

Fig. 6 Reputation concept on VP and its possible relation to other areas

one." (Teacher 6, relating classification, association and play/affective areas).

"It is very interesting to know the opinion of the other participants, but it must be only an indication of quality because not always the best contribution is the one we selected." (Teacher 2, relating classification, exploitation and association areas).

"I think it is very useful to know the quality of the contributions, because I consider quality as something extremely important" (Teacher 4, relating classification and subsistence areas).

"I am interested in knowing the opinion of other users, mainly the ones I like" (Teacher 5, also relating classification with association and play/affective areas).

The analysis suggested that a mechanism for supporting identification of quality and relevance should be positive, i.e., the presence of recognition must distinguish a contribution from others, but the absence of recognition is not necessarily negative. The first version of TNR was featured with possibilities to like comments, adding content items to a favourite list, following interesting users, assigning someone for help and promoting the best contributions according to users' opinion, without penalising those not promoted. If we had ignored teachers' cultural view on reputation mechanisms, the designed features could have been rejected by them, or even worst, they could have triggered negative behaviours and emotions that would turn teachers away from the system, discouraging their participation and interaction. 


\section{Discussion}

"...neither a computer nor the teaching of computer science has any value or meaning outside of its impact on people." (Lee 1989).

The ubiquitous and extreme impact of technology on people's lives in the contemporary world, more than ever, requires from us ICT researchers and practitioners to assume the responsibility for designing technologies that contribute to improving peoples' and communities' lives in a way that makes sense to them, and avoiding triggering adverse effects by the introduction of novel technologies. As previously discussed, a technical-centred perspective on ICT narrows our understanding of the context in which it is/will be introduced, making it difficult to anticipate desirable (or undesirable) impacts and consequences on users and stakeholders. We cannot detach a technology from the cultural context in which it was designed and delivered.

Distinct in nature and purpose, the two case studies introduced in this article illustrate that a sociocultural approach is not tied to any design process. While the TNR design relied mainly on co-creation with teachers mediated by a culture-based artefact, the SEETree creation required analysing secondary and quantitative data from surveys and studies from the literature to shape the design. In both cases, Organisational Semiotics (Liu 2000) provided us with the lenses to see beyond technical aspects, mapping also formal and informal forces that impacted on the social issue we were tackling, and the interaction between these forces.

Both the SEETree and TNR are part of technical information systems embedded in other systems and infrastructures. They automate tasks, process and provide information, and operate according to a set of pre-defined norms, rules and restrictions part of more complex formal systems. Such formal systems encompass business norms, laws, regulating entities and well-accepted social behaviours, which determine what is allowed, expected, forbidden, and accepted either for raising energy awareness or for discussing real cases of students with special needs. The explanation, or justification, for the formal systems relies on the informal aspects, where people develop their values and wherefrom their needs originate. The informal information systems are where subjectivity is manifested and where the true impact of ICT on people's life is perceived. They explain why people would be happy to see and interact with the SEETree but could reject a simple energy monitoring system, and why teachers are happy to share their ideas and help each other, but would reject a TNR feature that omitted to duly acknowledge their contribution.
Hall's (1959) Primary Message Systems has been another theoretical and analytical support framework for our researches and practices. Hall's framework is abstract and covers almost any thinkable aspect of a design context. On the one hand, it may require further readings and examples to be applied. On the other hand, to the best of our knowledge, not only does it cover aspects of other cultural approaches we reported on (e.g., Hofstede 2005; Beyer and Holtzblatt 1997), but also enables looking beyond predefined assumptions and thus helps to reveal issues from the design context that would have otherwise remained hidden. Hall's ten areas of culture invite us to inquire about behavioural patterns, values, customs, materials, resources, etc., and how they are related to each other, remaining open to serendipity, to every interesting new aspect that may emerge. The TNR's letter of principles is an example of a co-created by product that emerged from the participatory practices, reflecting a set of both existing and desired values.

Instantiated in each case study reported, the socially aware computing approach from Baranauskas (2009, 2014) allowed us to articulate ICT development in relation to the social practices enacted by stakeholder representatives. It enabled us to employ culture-based artefacts as part of a design process with other activities and demands. The artefacts were created/adapted to support research in situated and participatory practices, to facilitate problem understanding, solution proposal, requirements elicitation, and formalisation from a culturally enriched perspective.

In the energy awareness case study, this approach revealed that tackling energy savings within that community would be in vain if the solution was not considering the problematic relationship some people have with energy providers and the "culture" of fraud, formal, and informal aspects. Also, it disclosed cultural barriers that needed to be overcome to trigger users' motivation towards protecting the environment, such as the need to evidence the importance of individual contributions and collaboration towards a collective global achievement. The areas of culture guided design decisions properly associating the right media to the right group of users, for instance adding tangible elements to expand engagement, identifying local elements that influenced graphical design (using trees, dams, flooding, etc.), to name a few. In contrast to traditional design approaches, we went beyond design implications, addressing also design intentions by properly mapping current and intended behaviour.

Similarly, in the second case study, the culture-based artefacts brought to surface aspects that would hardly be evident using a "conventional" approach to design. It enabled an understanding of users' cultural views regarding important concepts, more directly suggesting features for a social platform. It revealed the need to look at "well 
known" concepts for researchers (e.g., privacy, reputation, sharing) from the community perspective, evidencing differences in the value attached to such concepts.

We recognise that it is not always possible to include end users in the design process due to a wide range of factors. In such case, adopting culturally informed artefacts is even more important to support an engagement with the design problem and to envision solutions through the lenses of the different stakeholders. Reflecting the amplitude and complexity of the concept of culture, there are no deterministic rules for informing ICT design with cultural aspects. The selection and application of strategies, methods, and artefacts should consider many contextual elements such as resources available and stakeholder goals. We described the applicability of different artefacts within a Socially aware perspective to support designers in a broad sense and considering a multiplicity of scenarios. Nonetheless, we recognise that further investigations can still refine the artefacts and their applicability to different design processes.

\section{Conclusion}

Wide in its meaning and number of definitions in the literature, "Culture" has been extensively investigated from quite different perspectives in different domains. In this paper, we were not pursuing an ultimate definition, and do not intend to unify the perspectives in ICT design. Instead, we presented our approach for informing design with cultural aspects in practical terms considering our theoretical and methodological grounds.

Respecting cultural aspects when conceiving a technology, analysing possible positive and negative impacts of technology adoption by a social group, and investigating methods and artefacts to support these activities are both a need and a challenge for all those involved with ICT design. In fact, if we look at technology as a cultural construct that permeates human life, and if we recognise how interactive technology has changed our lives, then this is a subject that directly or indirectly affects everyone. A technology cannot be detached from its cultural context. Technology is produced through intentional and rational processes influenced by the cultural background of different stakeholders, no longer only for solving problems and automating tasks, but also for mediating complex social interactions, boosting creativity, play, learning, etc. Therefore, the concern with technical artefacts cannot be restricted to their designed functionalities, but needs to encompass as well how it is going to affect our lives and our social environment. Thus, this paper presented reflections, artefacts, and real examples with the intention to sensitise people involved in ICT design to the importance and benefits of considering cultural elements.

When choosing a frame of reference to talk about culture, we are already shaping our view and our discourses; when we adopt a theoretical and methodological ground, we are looking at a subject from a specific angle, which entitles us to see some parts of the whole picture. Therefore, we must make clear from what perspective we are looking at the subject. To this end, we briefly discussed what we consider as culture in the context of technology design, why we think it is important to take it into account in ICT design, and how it has been addressed in our work and other studies in the literature.

We subscribe to a systemic view placing the technical solution as part of a more complex social system. We argue that it is important to understand the informal and formal aspects of the design context as profoundly and broadly as possible, considering cultural issues as an "insider" when designing ICTs. If we are able to understand how people live and interact, develop their values and needs, their expectations, desires, beliefs, etc. in a situated scenario, then we may be able to design and introduce technology that is appropriate for people in their cultural settings in an informed and responsible way.

The two case studies presented illustrate that a culturally informed perspective to design can go beyond an informative analysis and can be integrated throughout different design processes. We introduced four culture-based artefacts: the Organisational Onion to understand the problem; the Primary Message Systems, based on Hall's (1959) definition of culture, to translate cultural aspects into technical requirements; norms definition to map current and desired patterns of behaviour; and the Value Pie, an artefact to support understanding the problem and the context from three different perspectives: the cultural nature according to Hall's area of culture, level of formality (technical, formal and informal), and the interplay of cultural aspects. In the case studies, we evidenced the benefits and outcomes of this approach.

From conception to development, evaluation, and adoption, the design process must be supported by artefacts that help identifying cultural aspects and translate them into sociotechnical requirements. Selecting which artefacts are suitable to a design context is itself a result from the process of understanding design problems, reinforcing the social nature of a design process that starts in society and will reflect back on it.

Although the artefacts presented have been explored in other contexts and case studies - e.g., Baranauskas and Bonacin (2008), Miranda et al. (2010), Pereira et al. (2015), Piccolo et al. (2017) — further studies with more participants, in different contexts, and investigating the impacts of technology on different stakeholders can certainly 
contribute to refine the socially aware approach. These may include further investigations about the constitution of the TNR social network, and future instances of the SEETree within other communities, as well as applications of the culture-based artefacts to different cases and contexts. More than describing the "correct way" of using the culture-based artefacts, we expect this to inspire further researches to not only reproduce the artefacts applications, but also to adapt, create and combine with new design processes and contexts, sharing new examples and outcomes produced from their application.

Acknowledgements The authors thank their colleagues, research groups, institutions and students for the support throughout their research; a special thanks to M.C.C. Baranauskas for her inspiring ideas and critical feedback. The authors also thank editors and anonymous reviewers for their constructive contributions.

Open Access This article is distributed under the terms of the Creative Commons Attribution 4.0 International License (http:// creativecommons.org/licenses/by/4.0/), which permits unrestricted use, distribution, and reproduction in any medium, provided you give appropriate credit to the original author(s) and the source, provide a link to the Creative Commons license, and indicate if changes were made.

\section{References}

Globo O (2015) Arndt Vonstaa: Erros Grosseiros. Accessed 25 Nov 2016. (in Portuguese)

Almeida AC (2007) A Cabeça do Brasileiro. Record, Rio de Janeiro, p 208 (in Portuguese)

Bannon L (2011) Reimagining HCI: toward a more human-centered perspective. Interactions 18(4):50-57

Baranauskas MCC (2009) Socially Aware Computing. In: Proc. of VI international conference on engineering and computer education, pp 1-5

Baranauskas MCC (2014) Social awareness in HCI. Interactions 21(4):66-69

Baranauskas MCC, Bonacin R (2008) Design—indicating through signs. Design Issues 24:30-45

Barth F (1969) Ethnic Groups and Boundaries. Little, Brown, Boston

Beyer H, Holtzblatt K (1997) Contextual design: defining customercentered systems. Elsevier, San Francisco

Bødker S (2006) When second wave HCI meets third wave challenges. Proceedings of 4th Nordic conference on Humancomputer interaction: changing roles, Norway. ACM Press, Oslo, pp 1-8

Bødker S (2015) Using IT to 'do good' in communities? J Community Inf 11(2). Retrieved from http://ci-journal.net/index.php/ciej/ article/view/1151/1146

Bødker S, Kristensen JF, Nielsen C, Sperschneider W (2003) Technology for Boundaries. In: Proc. of the 2003 international conference on supporting group work (GROUP'03), ACM, pp 311-320

Del Gado E, Nielsen J (1996) International users interface. Wiley, New York

Gasparini I, Pimenta MS, Palazzo JMO (2011) Vive la différence!: a survey of cultural-aware issues in HCI. In: Proc. of the $\mathrm{X}$ Brazilian symposium on human factors in computing systems, pp 13-22
Gurstein M (2007) What is community informatics (and why does it matter)?. Polimetrica, Milan

Halabi A, Sabiescu A, David S, Vannini S, Nemer D (2015) From exploration to design: aligning intentionality in community informatics projects. J Community Inf 11(3). Retrieved from http://www.ci-journal.net/index.php/ciej/article/view/1160/1156

Hall ET (1959) The Silent Language. Doubleday, New York

Hall ET (1977) Beyond culture. Doubleday, New York

Hofstede G (2005) Cultures and organizations: software of the mind, 2nd ed. McGraw-Hill, New York

Holtzblatt K, Beyer HR (2013) Contextual Design. In: Soegaard Mads, Dam Rikke Friis (eds) The encyclopedia of humancomputer interaction, 2nd edn. The Interaction Design Foundation, Aarhus

Isomursu M, Ervasti M, Kinnula M, Isomursu P (2011) Understanding human values in adopting new technology — a case study and methodological discussion. Int $\mathbf{J}$ Hum Comput Stud 69(2011):183-200

Kamppuri M, Bednarik R, Tukiainen M (2006) The expanding focus of HCI: case culture. In: Proc. of the 4th Nordic conference on human-computer interaction: changing roles (NordiCHI '06), ACM, pp 405-408

Kolkman M (1993) Problem articulation methodology. PhD Thesis, University of Twente, Febo, Enschede

Lee E (1989) Some suggestions on a computer science undergraduate curriculum. In: COMPCON Spring'89. Thirty-Fourth IEEE computer society international conference: intellectual leverage, Digest of Papers. p 366

Leidner DE, Kayworth T (2006) Review: a review of culture in information systems research: toward a theory of information technology culture conflict. MIS Quarterly 30:357-399

Liu K (2000) Semiotics in Information Systems Engineering. Cambridge University Press, New York

Marcus A (2001) International and intercultural user interfaces. In: Stephanidis C (ed) Users Interfaces for all: concepts, methods and tools. Lawrence Erlbaum, New Jersey, pp 47-63

Miranda LC, Hornung H, Baranauskas MCC (2010) Adjustable interactive rings for iDTV. IEEE Trans Consum Electron 56:1988-1996

Murray R, Caulier-Grice J, Mulgan G (2010) The open book of social innovation. Young Foundation/NESTA, London

Papanek V (1971) Design for the real world. Thames and Hudson, London

Peirce CS (1867-1913) Collected papers of charles sanders peirce. In: Hartshorne C, Weiss P, Burks AW (eds) Harvard University Press, Cambridge, pp 1-8

Pereira R, Baranauskas MCC (2014) Value pie: a culturally informed conceptual scheme for understanding values in design. HumanComput Interact 8510:122-133

Pereira R, Baranauskas MCC (2015) A value-oriented and culturally informed approach to the design of interactive systems. Int $\mathbf{J}$ Human-Comput Stud 80:66-82

Pereira R, de Miranda LC, Baranauskas MCC, Piccolo LSG, Almeida LDA, dos Reis JC (2011) Interaction design of social software: clarifying requirements through a culturally aware artifact. In: 2011 international conference on information society (i-Society), pp. 293-298

Pereira R, Baranauskas MCC, Liu K (2015) The Value of Values for HCI: an informed discussion beyond philosophy. In: Proc. of the 14th Brazilian Symposium on human factors in computing systems IHC 2015, Brazilian Computer Society, 430-439

Piccolo LSG, Baranauskas MCC (2011) Motivational Aspects in Energy Feedback Systems Design. In: Proc. of the 10th Brazilian Symposium on human factors in computing systems and the 5th latin american conference on human-computer interaction (IHC + CLIHC 2011), Brazilian Computer Society, pp 313-322 
Piccolo LSG, Scharl A, Baranauskas MCC (2012) Design of EcoFeedback Technology to Motivate Sustainable Behavior: Cultural Aspects in a Brazilian Context. In: Proc. of Intern. Conf. on Infor. Resources Manag. (Conf-IRM'12)

Piccolo LSG, Hornung H, Baranauskas MCC, Pereira R (2013) Designing to Promote a New Social Affordance for Energy Consumption. In: Proc. of 12th IFIP conference on e-business, e-services, e-society. pp 213-225

Piccolo LSG, Baranauskas MCC, Azevedo R (2017) A socially inspired energy feedback technology: challenges in a developing scenario. AI \& Soc 32(3):383-399

Pipek V, Avram G, De Cindio F (2016) Introduction. Interactions 23(1):34-35

Rogers Y (2012) HCI Theory. In: Classical, modern, and contemporary. Morgan \& Claypool, San Rafael, p 131

Salgado LCC, Souza CS, Leitão CF (2011) On the Epistemic Nature of Cultural Viewpoint Metaphors. In: Proc. of X Brazilian Symposium on Human Factors in Computer Systems, pp 23-32

Salgado LCC, de Souza CS, Leitão CF (2013) A journey through cultures: metaphors for guiding the design of cross-cultural interactive systems. Springer, London

Salgado L, Pereira R, Gasparini I (2015) Cultural issues in HCI: challenges and opportunities. In: Kurosu M (ed) Humancomputer interaction: design and evaluation, HCI 2015. Lecture Notes in Computer Science, vol 9169. Springer, Cham, pp 60-70
Schuler D, Namioka A (1993) Participatory design: principles and practices. Lawrence Erlbaum Associates, Hillsdale

Sellen A, Rogers Y, Harper R, Rodden T (2009) Reflecting human values in the digital age. Commun ACM 52:58-66

Sharp L (1952) Steel Axes for Stone-Age Australians. Human Organization. 11(2):17-22

Stamper RK (1993) Social norms in requirements analysis-an outline of MEASUR. Requirements Engineering Technical and Social Aspects. Academic Press, New York

Stamper RK (2001) Organisational semiotics: informatics without the computer? Information, organisation and technology: studies in organisational semiotics. Kluwer Academic Publishers, Boston

Stamper R, Liu K, Hafkamp M, Ades Y (2000) Understanding the roles of signs and norms in organizations-a semiotic approach to information systems design. Behav Inf Technol 19(1):15-27

Tylor EB (2010) Primitive culture: researches into the development of mythology, philosophy, religion, art, and custom. Cambridge University Press, Cambridge

Winograd T (1997) The design of interaction. In: Beyond calculation: the next fifty years of computing. Springer, New York, pp 149-161

Winschiers H, Fendler J (2007) Assumptions considered harmful: The Need to Redefine Usability. In: 2nd international conference on usability and internationalization, pp 22-27

Yeo AW (2000) Are usability assessment techniques reliable in nonwestern cultures? Electron J Inf Sys Dev Ctries 3(1):1-21 